\title{
Possible disease-modifying factors: the mannan-binding lectin pathway and infections in hereditary angioedema of children and adults
}

\author{
Maciej Cedzyński ${ }^{1}$, Kazimierz Madaliński', ${ }^{3}$, Hanna Gregorek², Anna S. Świerzko ${ }^{1}$, \\ Ewa Nowicka ${ }^{2}$, Krystyna Obtułowicz ${ }^{4}$, Katarzyna Dzierżanowska-Fangrat ${ }^{2}$, \\ Urszula Wojda ${ }^{2}$, Daniel Rabczenko ${ }^{5}$ and Masaya Kawakami ${ }^{6}$ \\ ${ }^{1}$ Laboratory of Immunobiology of Infections, Center of Medical Biology, Polish Academy of Sciences, Łódź, Poland \\ 2 Departments of Clinical Microbiology and Immunology; Allergology, Child Health Memorial Institute, Warsaw, Poland \\ ${ }^{3}$ Department of Immunopathology, National Institute of Hygiene, Warsaw, Poland \\ ${ }^{4}$ Department of Industrial Allergology, Jagiellonian University Medical School, Cracow, Poland \\ ${ }^{5}$ Department of Medical Statistics, National Institute of Hygiene, Warsaw, Poland \\ ${ }^{6}$ Kitasato University, Sagamihara, Japan
}

Received: 2007.01.09, Accepted: 2007.10.25, Published online first: 2008.02.05

\begin{abstract}
Introduction: Hereditary angioedema (HAE) is caused by mutations in the Clinh gene, leading to dysfunction of the C1-esterase inhibitor (C1-INH). C1-INH interacts with MASP-1 and MASP-2 proteases, participating in the mannan-binding lectin (MBL) pathway of complement activation. The aim of the study was to investigate the contribution of possible changes in MBL/MASP-2 complex activity and Helicobacter pylori, hepatitis B virus (HBV), and hepatitis C virus (HCV) infections to the severity and frequency of clinical symptoms of HAE.

Materials and Methods: The study was performed in 65 patients with HAE and 113 healthy persons. The parameters measured were C1-INH, C4, MBL concentration and MBL/MASP-2 complex activity, and serological markers of $H$. pylori, HBV, and $\mathrm{HCV}$ infection. Scores for the frequency and severity of HAE symptoms were determined.

Results: HAE scores were significantly higher in patients whose C1-INH activity did not exceed $10 \%$ than in patients with activity of $10-52 \%(\mathrm{p}=0.016)$. No significant differences were found in the median levels of MBL concentration and MBL/MASP-2 complex activity between patients and the control group. There was a slight association between contact with H. pylori in patients and HAE symptom score ( $\mathrm{p}=0.052$, not significant). Adult patients showed a 2.6-times higher frequency of anti-HBc than the general population. HBV DNA was negative in anti-HBc(+) patients.

Conclusions: These results suggest that the MBL complement activation pathway itself does not contribute to the frequency of angioedema attacks. Infections with H. pylori and HBV may slightly influence the disease score (not significant).
\end{abstract}

Key words: hereditary angioedema, C1-inhibitor, mannan-binding lectin complement pathway, H. pylori, hepatitis B and C infections.

Abbreviations: C1-INH - C1-inhibitor, CP - classical pathway, EACA - $\varepsilon$-aminocaproic acid, HAE - hereditary angioedema, $\mathrm{HBV}$ - hepatitis B virus, $\mathrm{HCV}$ - hepatitis C virus, MBL - mannan-binding lectin, MASP - MBL-associated serine protease.

Corresponding author: Prof. Kazimierz Madaliński, Department of Clinical Microbiology and Immunology, Child Health Memorial Institute, Al. Dzieci Polskich 20, 04-736 Warsaw, Poland, tel.: +48 22 815-72-70, fax: +48 22 815-7 2-75, e-mail: kmadalinski@wp.pl

\section{INTRODUCTION}

Hereditary angioedema (HAE) is a rare primary immunodeficiency disorder clinically characterized by self-limiting, recurrent, acute, non-allergic edematous episodes of the face, extremities, trunk, larynx, gastrointestinal tract, and/or genitals. The disease is caused by mutations (e.g. point mutations, deletions, partial duplications) in the gene of the $\mathrm{C} 1$ esterase inhibitor (C1-INH) [8], leading to reduced synthesis or loss of biological function. Angioedema may be caused by a partial deficit of C1-INH (type 1) or the presence of normal or excessive amounts of this regulatory protein with impaired function (type 2) [2, 24]. C1-INH deficiency 
leads to uncontrolled activation of the classical pathway (CP) of complement and bradykinin, a factor having potent vasodilatory activity. Bradykinin is considered today as the major mediator of edema in $\operatorname{HAE}[7,13]$. Indeed, elegant studies by Zahedi et al. [29] strongly suggest that activation of the complement system alone (without involvement of the contact system) does not cause angioedema. It is believed, however, that external factors, such as surgical procedures, physical and psychical trauma, tissue injury, and/or infections leading to the activation of complement, contact, and/or fibrinolytic cascades may cause C1-INH consumption [2]. These triggers may result in an overwhelming, acute generation of vasoactive peptides such as bradykinin [2, 7, 13].

Mannan-binding lectin (MBL) is generally known as a pattern-recognition molecule protecting the host from infection by direct opsonization of microorganisms or by microbial lysis through complement activation [5, 20, 23]. The C1-INH molecule is also supposed to regulate the MBL pathway via inhibition of MBL-associated serine proteases (MASPs), of which MASP-2 cleaves C4 much more efficiently than $\mathrm{C} 1$ s does [22]. Thus MBL pathway overactivation leading to $\mathrm{C} 1-\mathrm{INH}$ consumption by MASPs might be one of the factors modifying HAE, i.e. it may influence the age of onset of the first manifestation as well as the frequency and/or severity of attacks. Furthermore, assessment of MBL-lectin pathway parameters was undertaken to analyze whether MBL deficiency, by contributing to increased susceptibility to numerous infectious diseases $[3,4,15,16,19$, 27], might be associated with the frequency and severity of edematous attacks.

As mentioned, factors such as infections may cause C1 inhibitor consumption. In fact, an influence of common infections, such as by Helicobacter pylori (H. pylori), on the frequency and severity of HAE attacks was observed [9]. As has been reported, successful eradication of $H$. pylori resulted in a fivefold reduction in or complete disappearance of HAE symptoms [9]. Many infectious diseases resulting in enhanced antibody response and the formation of immune complexes may trigger the overuse of already reduced $\mathrm{C} 1$-INH $[2,9,10]$. Therefore the second objective of this study was to investigate whether exacerbations of acute HAE could be initiated by stimulation of the immune response by infectious agents, leading to complement activation and depletion of C1-INH. Infections with $H$. pylori, hepatitis B (HBV), and hepatitis C (HCV) were investigated for their possible contribution to edema frequency or severity in HAE patients.

\section{MATERIALS AND METHODS}

\section{Patients}

Patients were diagnosed according to the criteria proposed by Cicardi and Zingale [6]. Serum and plasma samples from 65 patients were investigated. The samples were taken during remission of symptoms. The patients were 19 children (age range: 4.5-18 years, median: 12 years) and 46 adults (age range: $19-74$ years, median: 36 years). Sixty patients belonged to 28 families, four patients were cases without a family history, and one patient had two family members with abdominal symptoms but samples from them were not available for laboratory testing. The clinical symptoms most often observed were edema of the skin and subcutaneous tissues, mucous membranes of the gastrointestinal tract, and genitals, as well as of the brain (rather in children), pharynx, and larynx. Brain involvement manifested as insomnia, headaches, and temporary unconsciousness.

Sixty-one patients suffered from type $1 \mathrm{HAE}$ and two children and two adults (three of whom belonged to one family) were diagnosed with type 2. Approval of the Ethics Commission of the Child Health Memorial Hospital and informed patient consent were obtained.

\section{Reference group}

Healthy children $(n=33$, age range: $1-16$ years, median: 7 years), receiving no medication and attending the hospital for reasons unconnected with infections or edema, were included in the control group for the MBL study. Blood was taken during the control examination. Samples from adult blood donors $(n=80$, age range: 18-65 years, median: 28 years) who had a medical examination at the Institute of Hematology, Warsaw, were taken for comparison of MBL level and activity. The reference group for the study of anti- $H$. pylori IgG antibodies were 636 children aged 10-12 years, unselected for health status [17]. For the study of anti-H. pylori $\mathrm{IgG}$ antibodies in adults, the reference group consisted of 3307 persons representing the Polish population [17].

\section{Symptom scores}

The severity score of HAE symptoms (1-6) was defined as: 1-2 with few signs (e.g. small edema of extremities), 3-4 with medium signs (edema of different parts of the body, gastrointestinal tract involved), and 5-6 with severe edemas of several organs, involving the brain and larynx being frequent and life-threatening. Symptoms were further evaluated by a frequency score (1-6), i.e. 1 with attacks once a year, 2 every 6 months, 3 every 3 months, 4 every 2 months, 5 every month, and 6 every week.

\section{Treatment}

Of the 19 C1-INH-deficient children described in this paper, 11 were not being treated because of lack of symptoms. The rest were on maintenance treatment with $\varepsilon$-aminocaproic acid (EACA), with a combination of EACA and danazol (100-200 mg/daily), or with tranexamic acid. Of the $46 \mathrm{C} 1$-INH-deficient adult subjects, 14 were not being treated (one with type 2) because of no or mild symptoms. Of the remaining 32 persons (one with type 2$)$, the majority received danazol alone $(n=24)$ or in combination with tranexamic acid $(n=2)$. Five patients 
were on other drugs: tranexamic acid $(n=3)$ and EACA $(\mathrm{n}=2)$. One patient received intravenous infusions of C1-INH concentrate twice (1000 U each time, Berinert); the blood sample was taken after half a year.

\section{Assessment of C1-INH and C4}

This was performed in sera by the nephelometric method using a BN Prospec nephelometer (Dade Behring, Germany). Activity of C1-INH esterase was measured by the photometric method using a Technochrome C1-INH Kit (Technoclone GmbH, Vienna, Austria). The result was expressed as the percentage of the normal human serum activity [18]. The reference values applied for serum samples from healthy persons were C1-INH (antigen): 0.20-0.32 g/l, C1-INH (activity): $70-130 \%$, and C4: $0.15-0.55 \mathrm{~g} / \mathrm{l}$. The Department of Clinical Microbiology and Immunology, Child Health Memorial Institute, Warsaw, took part in the external quality testing of C1-INH, coordinated by the Central Laboratory for Blood Transfusion (Sanquin Blood Supply Foundation, Amsterdam, Netherlands).

\section{Determination of $M B L$ concentration in sera and $M B L / M A S P-2$ complex activity}

MBL concentrations were determined using ELISA as previously described [4]. Activity of the MBL/MASP-2 complexes was assessed by $\mathrm{C} 4$ deposition and was essentially performed as described elsewhere [4]. A high-ionicstrength buffer was used to exclude $\mathrm{CP}$ activation [21]. The results depend on MBL/MASP-2 complex concentrations and arrangement, but they do not depend on $\mathrm{C} 4$ or C1-INH serum levels/activity [25]. Thus they reflect MASP-2's potency to cleave C4. Such a procedure avoids the effect of C1-INH deficiency as well as the consumption of endogenous $\mathrm{C} 4$ and other complement system factors.

\section{Investigation of HBsAg and antibodies specific to infectious agents}

Serological markers of $\mathrm{HBV}$ and $\mathrm{HCV}$ infection, i.e. HBsAg and IgG anti-HBc and anti-HCV antibodies, were determined by the respective Microparticle assays AXSYM (Abbott, IL, USA) according to the manufacturer's instructions. Measurement of anti-H. pylori was performed by ELISA (Mikrogene, Germany). Positive results for IgG anti-H. pylori antibodies were $>24 \mathrm{U} / \mathrm{ml}$, the gray zone was $20-24 \mathrm{U} / \mathrm{ml}$, and negative results were $<20 \mathrm{U} / \mathrm{ml}$.

\section{Investigation of $H B V-D N A$}

HBV-DNA was searched for using the commercially available, semi-automated HBV-DNA PCR assay (Cobas Amplicor HBV Monitor, Roche Diagnostic Systems, USA) according to the manufacturer's instructions. The limit of detection was 200 copies per $\mathrm{ml}$ of HBV-DNA and each run included appropriate positive and negative controls according to the test requirements.

\section{Statistical analysis}

Median serum MBL concentrations, MBL pathway activity, symptom scores, and C4 levels between the various groups were compared with the Mann-Whitney U-test (rank test) because of the lack of a normal distribution. The Bonferroni correction was used for the analysis of C1-INH (antigen and activity) and C4 levels in the treated and untreated patients. The procedure for applying the Bonferroni correction was to calculate the p-values, multiply them by the number of tests, and set values below 0.05 as significant, which is equivalent to division of the level of significance by the number of tests. Correlations between analyzed parameters were assessed using Spearman's correlation coefficient and the test of its significance. $p$ Values $<0.05$ were considered statistically significant.

\section{RESULTS}

Complement components and scores of HAE symptoms

Table 1 lists the laboratory parameters of the patients. Values of the $\mathrm{C} 4$ component in untreated and

Table 1. C1-INH concentration, C1-INH activity, and C4 concentration in children and adults with type 1 and type 2 HAE

\begin{tabular}{lccc}
\hline \multicolumn{1}{c}{ Group examined } & $\begin{array}{c}\text { C1-INH, g/1 } \\
\text { median (range) }\end{array}$ & $\begin{array}{c}\text { C1-INH activity, } \\
\% \text { median (range) }\end{array}$ & $\begin{array}{c}\text { C4, g/l } \\
\text { median (range) }\end{array}$ \\
\hline $\begin{array}{l}\text { Children with type 1, } \\
\text { untreated (n=11) }\end{array}$ & $0.08(0.02-0.43)$ & $10 \%(5-43)$ & $0.06(0.01-0.11)$ \\
$\begin{array}{l}\text { Children with type 1, } \\
\text { treated (n=8) }\end{array}$ & $0.045(0.03-0.08)$ & $7 \%(0.1-18)$ & $0.05(0.04-0.05)$ \\
$\begin{array}{l}\text { Adults with type 1, } \\
\text { untreated (n=13) }\end{array}$ & $0.065(0.02-0.27)$ & $11 \%(0.1-34)$ & $0.075^{*}(0.01-0.15)$ \\
$\begin{array}{l}\text { Adults with type 1, } \\
\text { treated (n=31) }\end{array}$ & $0.065(0.03-0.24)$ & $10 \%(0.1-40)$ & $0.05^{*}(0.01-0.11)$ \\
Patients with type 2a & $0.41-0.69$ (range) & $10-34 \%$ (range) & $0.04-0.10($ range) \\
\hline
\end{tabular}

a Two children and two adults; ${ }^{*} \mathrm{p}<0.05$, after Bonferroni correction $\mathrm{p}>0.05$. 
treated adults differed, being lower in the treated subjects. The difference was significant $(p<0.05$; after Bonferroni correction, $\mathrm{p}$ became $>0.05)$. There was a strong positive correlation between $\mathrm{C} 1$-INH antigen concentration and C1-INH activity (Spearman's correlation test, $\mathrm{r}=0.57, \mathrm{p}<0.01)$ and negative correlations between these and the score of severity of symptoms $(\mathrm{r}=-0.33, \mathrm{p}=0.01$ and $\mathrm{r}=-0.31, \mathrm{p}=0.02)$, respectively. Also, the score of frequency of symptoms correlated with the score of their severity and with the C1-INH antigen concentration $(r=0.57$ and $r=-0.37, p<0.01$ in both cases).

It should be stressed that the disease symptom score was usually higher in individuals in whom C1-INH activity did not exceed $10 \%$ (median: 5 , mean: 4.5 ) than in persons with this activity over $10 \%$ (median: 3 , mean: $3.4 ; \mathrm{p}<0.05)$. When $\mathrm{C} 4$ concentrations, as expressed in $\mathrm{mg} / \mathrm{dl}$, were compared between individuals with juvenile type I HAE onset (below 10 years) and those in whom the first symptoms manifested after the age of 10 years, a significant difference was noted (medians: 5.25 and 6.5, means: 5.08 and $6.72 \mathrm{mg} / \mathrm{dl}$, respectively, $\mathrm{p}<0.05$ ). In contrast, the groups so defined did not differ significantly in C1-INH activity.

\section{MBL concentration, MBL/MASP-2 complex activity, and $C 4$ concentration}

MBL concentration and MBL pathway activity were measured in 178 subjects. These were 52 children (19 HAE patients and 33 controls) and 126 adults (46 HAE patients and 80 controls). The results are summarized in Table 2. These data show that there were no statistically significant differences in MBL concentration and MBL pathway activity between the healthy controls and the C1-INH-deficient individuals. Moreover, no differences were found when both groups were subdivided into children and adults (data not shown). Four C1-INH-deficient and four healthy persons were found to be MBL deficient (MBL serum concentration below 100 $\mathrm{ng} / \mathrm{ml})$. The clinical symptom scores of the MBL-deficient patients were between 1-6 and did not differ from those of C1-INH-deficient individuals without MBL

Table 2. MBL and MBL pathway parameters in children and adults

\begin{tabular}{lcc}
\hline $\begin{array}{c}\text { Group } \\
\text { examined }\end{array}$ & $\begin{array}{c}\text { MBL concentration } \\
(\mathrm{ng} / \mathrm{ml})\end{array}$ & $\begin{array}{c}\text { MBL pathway } \\
\text { activity }(\mathrm{mU})\end{array}$ \\
\hline $\begin{array}{l}\text { Healthy controls }(\mathrm{n}=113) \\
\text { median }\end{array}$ & 774 & 432 \\
range & $24-4016$ & $11-2459$ \\
1st-3rd quartile & $360-1429$ & $183-758$ \\
C1-INH-deficient individuals (n=65) & \\
median & 574 & 343 \\
range & $27-2057$ & $15-2192$ \\
1st-3rd quartile & $307-1111$ & $181-758$ \\
p value* & 0.11 & 0.94 \\
\hline
\end{tabular}

* Median of healthy controls vs. median of patients.

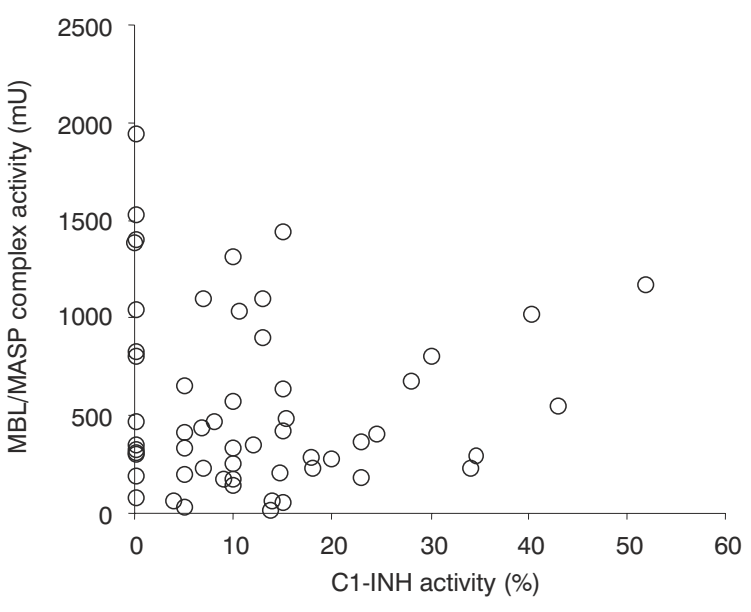

Fig. 1 Lack of correlation between C1-INH biological activity and complement MBL pathway activity.

deficiency. As expected, there was a strong positive correlation between MBL protein concentration and $\mathrm{MBL}$ protein activity (Spearman's correlation test, $r=0.82$, $\mathrm{p}<0.01$ in $\mathrm{C} 1$-INH-deficient and $\mathrm{r}=0.87, \mathrm{p}<0.01$ in healthy persons).

We also compared the values for C1-INH biological activity with those for MBL pathway activity in each patient, but no correlation was observed $(\mathrm{r}=-0.08$, $\mathrm{p}=0.56$; Fig. 1).

\section{Investigation of possible disease-modifying factors: the role of infections}

These examinations were performed in 19 children and 42 adults. The results are summarized in Table 3. IgG antibodies to $H$. pylori were found in $8 / 19$ children $(42.1 \%)$ and in $23 / 42$ adults $(54.8 \%)$. The median value of antibodies in children was $1560 \mathrm{U} / \mathrm{ml}$ (range: 51-3000) and in adults $134 \mathrm{U} / \mathrm{ml}$ (range: 24-2060). The high level of antibodies (above $1500 \mathrm{U} / \mathrm{ml}$ ) in 5 children and 4 adults is worth noting. The children with high values of $\operatorname{IgG}$ antibodies were in the age range of 5-17 years and four were $<10$ years. In the reference groups the presence of anti- $H$. pylori antibodies in 636 children was $31.5 \%$ and in 3307 adults $84.2 \%$. The difference between children with HAE and those in the reference group was not significant $(\mathrm{p}=0.33)$.

Table 3. Detection of anti-H. pylori antibodies and hepatitis B and hepatitis $\mathrm{C}$ serum markers in children and adults suffering from $\mathrm{HAE}$

\begin{tabular}{|c|c|c|c|c|c|}
\hline Group & $\begin{array}{c}\text { Age } \\
\text { (years) }\end{array}$ & $\begin{array}{l}\text { Anti- } \\
-H . \text { pylori } \\
\text { IgG }\end{array}$ & HBsAg & $\begin{array}{c}\text { Anti-HBc } \\
\text { IgG }\end{array}$ & $\begin{array}{l}\text { Anti- } \\
\text {-HCV }\end{array}$ \\
\hline $\begin{array}{l}\text { Children } \\
\mathrm{n}=19\end{array}$ & $\begin{array}{c}\text { median } \\
12\end{array}$ & $\begin{array}{l}42.1 \% \\
(8 / 19)\end{array}$ & 0 & $\begin{array}{l}5.3 \% \\
(1 / 19)\end{array}$ & 0 \\
\hline $\begin{array}{l}\text { Adults } \\
\mathrm{n}=42\end{array}$ & $\begin{array}{c}\text { median } \\
39\end{array}$ & $\begin{array}{l}54.8 \% \\
(23 / 42)\end{array}$ & 0 & $\begin{array}{l}16.7 \% \\
(7 / 42)\end{array}$ & 0 \\
\hline
\end{tabular}


The presence of anti- $H$. pylori antibodies in patients was accompanied by a higher score of HAE symptoms (median: 5, mean: 4.8 in positive vs. median: 4 , mean: 3.8 in negative persons). The difference was of borderline significance $(\mathrm{p}=0.052)$.

No serological markers of ongoing $\mathrm{HBV}$ and $\mathrm{HCV}$ infection were found in the studied individuals: $\mathrm{HBsAg}$ and anti-HCV antibodies were negative in all the cases. However, positive anti-HBc results were noted in 1/19 children $(5.3 \%)$ and $7 / 42$ adults $(16.7 \%)$. Together, of 61 persons checked for hepatitis $\mathrm{B}$ and $\mathrm{C}$ markers, 8 (13.1\%) showed anti-HBc antibodies. The 8 samples from patients positive for anti-HBc (one child and 7 adults) were tested for the possible presence of HBV DNA. All the samples proved to be negative. We compared the score of clinical symptoms between HAE patients negative and positive for anti-HBc antibodies. Although the anti-HBc(+) patients tended to have higher scores of severity than anti-HBc(-) patients, the difference was not significant $(p=0.1)$.

\section{DISCUSSION}

Hereditary angioedema is a rare (1:10000 to $1: 50000$ live births) but dangerous disease, which may be life threatening. Thus knowledge concerning various factors potentially influencing the frequency and severity of attacks is important. This study involved a relatively large group of HAE patients with C1-INH deficiency $(\mathrm{n}=65)$. The MBL complement activation pathway, similarly to the classical one, is possibly regulated by $\mathrm{C} 1$ -INH, interacting with MASPs, being homologues of $\mathrm{C} 1 \mathrm{r} / \mathrm{C} 1 \mathrm{~s}$. Moreover, both produce the same $\mathrm{C} 3$ convertase $(\mathrm{C} 4 \mathrm{~b} 2 \mathrm{a})$. Activation of the MBL pathway might therefore be an additional element which could worsen the status of persons with HAE and/or, due to C1-INH consumption, contribute to triggering attacks.

In the present study we compared MBL concentration and its ability to activate complement in C1-INH-deficient persons and a control group. No significant differences in median MBL concentrations and MBL/MASP-2 complex activities were found between patients and controls (Table 2). Thus our results, in general, may suggest that the MBL complement activation pathway itself does not contribute to the frequency and severity of attacks of HAE. It should be stressed that the assay system applied excluded the interference of endogenous $\mathrm{C} 4$ and $\mathrm{C} 1-\mathrm{INH}$ and thus reflected the activity of MBL/MASP-2 complexes. In consequence, the activation observed depended on MBL/MASP-2 complex concentration and arrangement (oligomerization, MASP content), reflecting the fact that the potential ability of the serum to initiate the MBL pathway did not correlate with C1-INH activity in patients. In contrast, in healthy subjects an active C1-INH protein regulates complement activity in vivo, so the serum potency determined in vitro may be higher due to the exclusion of endogenous C1-INH action. Thus the value determined in a patient may reflect a higher in vivo complement activation level than in a representative of the control group.

Another approach to studying the relationship of the contribution of the lectin pathway compared with the $\mathrm{CP}$ in HAE patients is to measure all the pathways simultaneously. Hungarian colleagues used this approach in 96 HAE patients and 30 healthy controls in whom MBL genotypes were also determined [28]. In their study, low MBL pathway activity in patients compared with controls was found. These authors, however, used another methodology which did not enable the exclusion of an influence of endogenous $\mathrm{C} 4$ and $\mathrm{C} 1$ -INH and, because of that, their results are difficult to compare with ours. It seems to be reasonable, however, that the data presented by Varga et al. [28] and in our paper do not conflict due to the described reasons. The activity of the CP correlated with the MBL pathway, but not with that of the alternative pathway in HAE patients' sera. Activity of the MBL pathway was lower in patients with onset of symptoms before the age of 10 years compared with those with onset over that age.

It was demonstrated that infection with $H$. pylori increases the susceptibility of HAE patients to attacks of angioedema $[9,10]$. Eradication of the infection caused a substantial decrease in attacks, especially of the bowel, in most of the patients [10]. Our study adds new data to these findings, concerning another population. The frequency of anti-H. pylori IgG antibodies in the HAE children $(42.1 \%)$ differed slightly (not significantly) from that in children of the general Polish population $(31.5 \%$, $\mathrm{p}=0.33$ ) [17]. The frequency of antibodies in adult patients corresponded to that in the general population [17]. The data from our study show that there was a slight association only between $H$. pylori infection and HAE appearance and/or intensity of symptoms. Thus it appears that the findings presented by the Hungarian authors, although spectacular, were probably exceptional and not completely confirmed in our investigation [9].

Hepatitis B and hepatitis C are relatively common viral infections in Poland, with a changing pattern, i.e. a constant increase in the proportion of $\mathrm{HCV}(0.8 \%$ $\mathrm{HBsAg}$ and $1.4 \%$ anti-HCV in the general population) $[11,14]$. Well-documented papers showed both HBV and $\mathrm{HCV}$ to form immune complexes in chronically infected patients $[1,26]$. Immune complexes of these viruses may affect the $\mathrm{CP}$ of complement, leading to a further reduction in C1-INH in HAE patients. In this study we did not find carriers of $\mathrm{HBsAg}$ or anti-HCV antibodies among the investigated patients, while IgG anti-HBc antibodies were found in 5.3\% of the C1-INH-deficient children and $16.7 \%$ of adults, respectively (Table 3). The presence of anti-HBc shows a previous contact with HBV. It appeared that adult C1-INH-deficient individuals showed a frequency of anti-HBc antibodies that was 2.6-times higher than in the general Polish population $(6.2 \%, \mathrm{p}<0.02)$ [11]. This may partly be explained by the fact that patients with HAE might be exposed to medical procedures such as blood sam- 
pling and the like. However, in none of the anti-HBc(+) samples was HBV-DNA detected. Thus it appears that some of our HAE patients had had contact with HBV, but did not have apparent infection, as evidenced by PCR. All our patients were negative for anti-HCV. We should stress that negative results for contact with $\mathrm{HCV}$ reflect the careful checking of products given to HAE patients [12].

In conclusion, our results indicate that MBL protein concentration and/or activity do not influence the score of angioedema attacks in patients with HAE. Of the infections studied there may be a slight association between contact with $H$. pylori in children and score of symptoms (not significant). Furthermore, we did not find $\mathrm{HBV}$ carriers or $\mathrm{HCV}$-infected persons in our patient group, which would have enabled analysis of the influence of these infections, but the increased frequency of anti-HB core antibodies in adult HAE patients in comparison with the general population may be meaningful.

Acknowledgment: This work was supported by grant 3/P05E/119/23 from the State Committee for Scientific Research (KBN, Poland). The results of this study were presented in part during the 12th International Congress of Immunology/4th Annual Conference of FOCIS, Montreal, July 2004, and at the 4th C1 Esterase Inhibitor Deficiency Workshop in Budapest, 2005. The skillful technical assistance of Ms. Ewa Balas and Ms. Bozenna Wołowska is gratefully acknowledged. We would like to warmly thank Prof. George Füst (Semmelweis University, Budapest, Hungary) and Dr. Peter Späth (ZLB Behring, Bern, Switzerland) for their efforts in critically revising the manuscript.

\section{REFERENCES}

1. Agnello V. (1995): The aetiology of mixed cryoglobulinemia associated with hepatitis $\mathrm{C}$ virus infection. Scand. J. Immunol., 42, 179-184.

2. Agostoni A., Aygoren-Pursun E., Binkley K. E., Blanch A., Bork K., Bouillet L., Bucher C., Castaldo A. J., Cicardi M., Davis A. E., De Carolis C., Drouet C., Duponchel C., Farkas H., Fay K., Fekete B., Fischer B., Fontana L., Fust G., Giacomelli R., Groner A., Hack C. E., Harmat G., Jakenfelds J., Juers M., Kalmar L., Kaposi P. N., Karadi I., Kitzinger A., Kollar T., Kreuz W., Lakatos P., Longhurst H. J., Lopez-Trascasa M., Martinez-Saguer I., Monnier N., Nagy I., Nemeth E., Nielsen E. W., Nuijens J. H., O'grady C., Pappalardo E., Penna V., Perricone C., Perricone R., Rauch U., Roche O., Rusicke E., Spath P. J., Szendei G., Takacs E., Tordai A., Truedsson L., Varga L., Visy B., Williams K., Zanichelli K., Zanichelli A. and Zingale L. (2004): Hereditary and acquired angioedema: Problems and progress. Proceedings of the third C1 esterase inhibitor deficiency workshop and beyond. J. Allergy Clin. Immunol., 114, S51-131.

3. Aittoniemi J., Miettinen A., Laippala P., Isolauri E., Viikari J., Ruuska T. and Soppi E. (1996): Age-dependent variation in the serum concentration of mannan-binding protein. Acta Paediatr., 85, 906-909.

4. Cedzynski M., Szemraj J., Swierzko A. S., Bak-Romaniszyn L., Banasik M., Zeman K. and Kilpatrick D. C. (2004):
Mannan-binding lectin (MBL) insufficiency in children with recurrent infections of the respiratory system. Clin. Exp. Immunol., 136, 304-311.

5. Chen C. B. and Wallis R. (2004): Two mechanisms for mannose-binding protein modulation of activity of its associated serine proteases. J. Biol. Chem., 279, 26058-26065.

6. Cicardi M. and Zingale L. (2004): Clinical manifestations of HAE. In: Hereditary and acquired angioedema: Problems and progress. Proceedings of the third C1 esterase inhibitor deficiency workshop and beyond. J. Allergy Clin. Immunol., 114, S55-S58.

7. Davis A. E. III (2005): The pathogenesis of hereditary angioedema. Clin. Immunol., 114, 3-9.

8. Drouet C., Blanch A., Roche O., Monnier N., Duponchel C., Kalmar L., Tordai A., Pappalardo E., Zingale L., Perricone R. and Lopez-Trascasa M. (2004): Mutation analysis of the CIINH gene. In: Hereditary and acquired angioedema: problems and progress. Proceedings of the third $\mathrm{C} 1$ esterase inhibitor deficiency workshop and beyond. J. Allergy Clin. Immunol., 114, S66-S74.

9. Farkas H., Gyeney L., Majthenyi P., Fûst G. and Varga L. (1999): Angioedema due to acquired C1-esterase inhibitor deficiency in a patient with Helicobacter pylori infection. Z. Gastroenterol., 37, 513-518.

10. Farkas H., Fûst G., Fekete B., Karadi I. and Varga L. (2001): Eradication of Helicobacter pylori and improvement of hereditary angioneurotic oedema. Lancet, 358, $1695-1696$.

11. Gaweda J., Klos M. and Kruszewski J. (1999): Epidemiological status of $\mathrm{HBV}, \mathrm{HCV}$ and CMV infections among blood donors - soldiers (in Polish). Lekarz Wojskowy, 75, 494-496.

12. Gompels M. M., Lock R. J., Abinun M., Bethune C. A., Davies G., Grattan C., Fay A. C., Longhurst H. J., Morrison L., Price A., Price M. and Watters D. (2005): C1 inhibitor deficiency: consensus document. Clin. Exp. Immunol., 139, 379-394.

13. Hack E. (2004): Pathogenesis of angioedema attacks. In: Hereditary and acquired angioedema: Problems and progress. Proceedings of the third $\mathrm{C} 1$ esterase inhibitor deficiency workshop and beyond. J. Allergy Clin. Immunol., 114, S75-S79.

14. Juszczyk J. (2005): Hepatitis C (in Polish). Termedia Medical Publishers, Poznań, 5-31.

15. Kielgast S., Thiel S., Henriksen T. B., Bjerke T., Olsen J. and Jensenius J. C. (2003): Umbilical cord mannan-binding lectin and infections in early childhood. Scand. J. Immunol., 57, 167-172.

16. Koch A., Melbye M., Sørensen P., Hømoe P., Madsen H. O., Mølbak K., Hansen C. H., Andersen L. H., Hahn G. W. and Garred P. (2001): Acute respiratory tract infections and mannose-binding lectin insufficiency during early childhood. JAMA, 285, 1316-1321.

17. Laszewicz W. (2003): Infection with Helicobacter pylori in Poland. Polish Society for Gastroenterology - study report.

18. Madalinski K., Sabbouh K., Chorazykiewicz M. and Gregorek H. (1991): C1-inh defect as an example of deficiency disease. Immunol. Invest., 20, 133-141.

19. Matsushita M. (1996): The lectin pathway of the complement system. Microbiol. Immunol., 40, 887-893.

20. Matsushita M. and Fujita T. (1992): Activation of the classical complement pathway by mannose-binding protein in association with a novel C1s-like serine protease. J. Exp. Med., 176, 1497-1502. 
21. Petersen S. V., Thiel S., Jensen L., Steffensen R. and Jensenius J. C. (2001): An assay for the mannan-binding lectin pathway of complement activation. J. Immunol. Methods, 257, 107-116.

22. Rossi V., Cseh S., Bally I., Thielens N. M. and Jensenius J. C. (2001): Substrate specificities of recombinant mannan-binding lectin-associated serine proteases-1 and -2. J. Biol. Chem., 44, 40880-40887.

23. Schwaeble W., Dahl M. R., Thiel S., Stover C. and Jensenius J. C. (2002): The mannan-binding lectin-associated serine proteases (MASPs) and Map19: Four components of the lectin pathway activation complex encoded by two genes. Immunobiology, 205, 445-466.

24. Späth P. and Wûthrich B. (1998): Inherited and acquired deficiencies of $\mathrm{C} 1$ esterase inhibitor in humans. In Rother K., Till G. and Hänsch G. (eds.): The complement system. Springer-Verlag, Berlin-Heidelberg, 353-410.

25. Thiel S., Moller-Kristensen M., Jensen L. and Jensenius J. C. (2002): Assays for the functional activity for the man- nan-binding lectin pathway of complement activation. Immunobiology, 205, 446-454.

26. Tsai J. F., Margolis H. S., Jeng J.-E., Ho M. S., Chang W. Y., Lin Z. and Tsai J. H. (1995): Circulating immune complexes in chronic hepatitis related to hepatitis $\mathrm{C}$ and $\mathrm{B}$ viruses infection. Clin. Immunol. Immunopathol., 75, 39-44.

27. Turner M. W. (1998): Mannose-binding lectin (MBL) in health and disease. Immunobiology, 199, 327-339.

28. Varga L., Szeplaki G., Kokai M., Laki J., Wieslander J., Daha M. and Füst G. (2005): Lectin pathway activity of complement is depressed in hereditary angioedema. IV C1 Inhibitor Deficiency Workshop, Budapest 2005, p. 66.

29. Zahedi R., Bissler J. J., Davis A. E. 3rd., Andreadis C. and Wisnieski J. J. (1995): Unique C1 inhibitor dysfunction in a kindred without angioedema. II. Identification of an Ala $443 \Rightarrow$ Val substitution and functional analysis of the recombinant mutant protein. J. Clin. Invest., 95, 1299-1305. 